\title{
VEGETAÇÃO EM ÁREAS URBANAS: BENEFÍCIOS E CUSTOS ASSOCIADOS.
}

\section{LUCIANA SCHWANDNER FERREIRA*}

*Arquiteta, Urbanista e Mestra na área de Tecnologia da Arquitetura pela Faculdade de Arquitetura e Urbanismo da Universidade de São Paulo. Email: luciana.swf@gmail.com

\section{RESUMO}

A necessidade de cidades mais verdes parece consensual, porém faz-se necessário compreender com maior profundidade os papéis da vegetação nas cidades e o impacto de sua presença no cotidiano de seus habitantes.

Ao levantar os principais benefícios e custos associados à presença da vegetação nas cidades este artigo objetiva contribuir com o planejamento das áreas verdes urbanas e com a valorização do verde nas cidades.

Palavras-chave: Vegetação Urbana; Floresta Urbana; Microclima Urbano; Conforto Ambiental; Impactos Ambientais.

\section{VEGETATION IN URBAN AREAS: BENEFITS AND ASSOCIATED COSTS}

\begin{abstract}
The need of greener cities seems to be consensual but it is necessary a deeper understanding of the role vegetation in the cities and the impact of its presence in everyday life of the inhabitants.

By raising the main benefits and associated costs with the presence of vegetation in the cities this article aims to contribute to the urban green areas planning and the enhancement of green in the cities.
\end{abstract}

Keywords: Urban Vegetation; Urban Forest; Urban Microclimate; Environmental Comfort; Environmental Impacts. 


\section{INTRODUÇÃO}

A importância geral da vegetação na ecologia urbana parece inquestionável, porém seus benefícios e os papéis que a vegetação desempenha nas cidades ainda carecem de maiores detalhamentos (SPANGENBERG, 2009).

A vegetação interage sobre o conjunto de elementos climáticos, contribuindo com diversos aspectos tais como controle da radiação solar, temperatura, umidade, poluição atmosférica, entre outros. Tipo, porte e idade da vegetação, bem como o período do ano são parâmetros importantes para determinar o grau de influência da vegetação no clima (MASCARÓ, 1996). Aparecem ainda como fatores determinantes dessa influência a relação área vegetada/área construída e a forma e arranjo do plantio (GIVONI, 1998).

Comumente classificados em ambientais ou sociais, os benefícios da vegetação urbana não receberão tal distinção no presente artigo por entendermos que em muitos aspectos os benefícios ambientais e sociais estão relacionados, sendo por vezes indissociáveis.

Distinção necessária é aquela a ser feita entre os efeitos ambientais de áreas verdes em geral e plantas em particular. Grandes áreas verdes, como parques, geralmente desempenham importante papel no estabelecimento da imagem da cidade e na provisão de área para atividades sociais. Porém, sua influência nos aspectos climáticos não vai muito além dos limites da área vegetada (GIVONI, 1998). Outra distinção necessária é aquela entre os efeitos das plantas no clima global da área urbana e os efeitos das áreas verdes nas condições microclimáticas do entorno dos edifícios e no desempenho térmico das construções (GIVONI, 1998).

A seguir serão apresentados alguns dos mais citados aspectos influenciados pela vegetação em áreas urbanas e os custos diretos e indiretos associados à sua presença nas cidades. 


\section{POLUIÇÃO ATMOSFÉRICA}

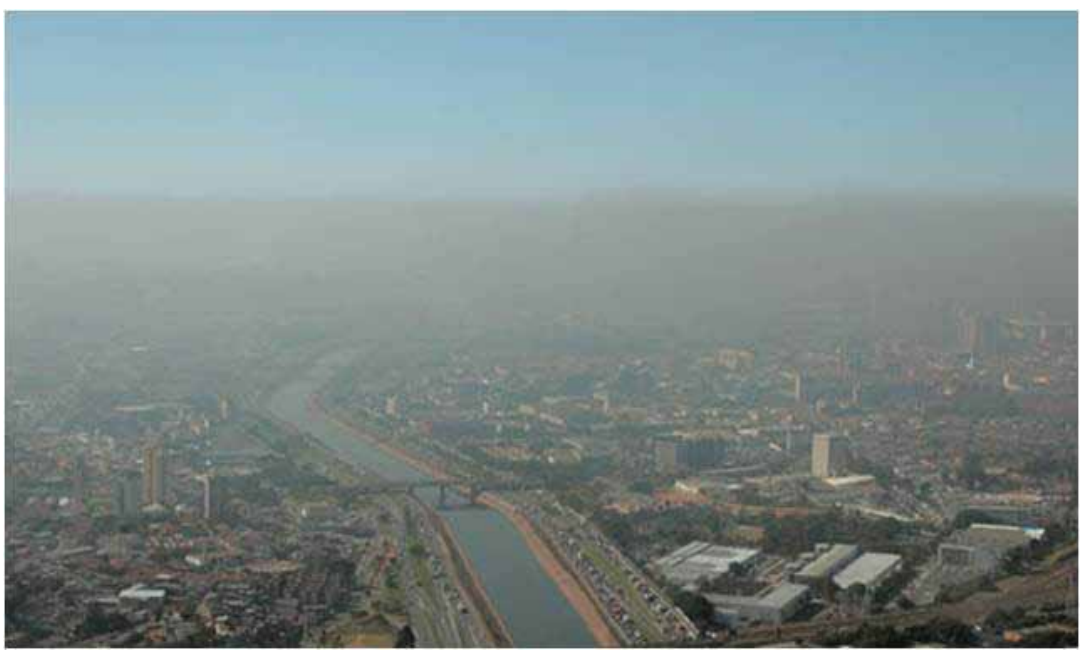

Figura 1 - Poluição atmosférica na cidade de São Paulo. Fonte: Agência Brasil, 2010.

A poluição atmosférica nas cidades compromete a saúde humana e já é considerada uma das principais causas de mortalidade por enfarto agudo do miocárdio e doenças respiratórias. Cardoso (2011) realizou um estudo na Zona Norte da cidade de São Paulo correlacionando os óbitos registrados pelas duas doenças citadas com a localização das vias de tráfego intenso, concluindo que há relação entre a concentração de poluentes e a mortalidade por enfarto e doenças respiratórias (informação verbal) ${ }^{1}$.

De acordo com Falcón (2007), em países desenvolvidos uma cidade de dimensões médias produz entre três e oito toneladas de dióxido de carbono $\left(\mathrm{CO}_{2}\right)$ /habitante/ ano, sendo o tráfego de veículos responsável por aproximadamente $40 \%$ do total de emissões. Além do $\mathrm{CO}_{2}$, a poluição atmosférica é formada ainda por óxidos de enxofre e de nitrogênio, monóxido de carbono, compostos orgânicos voláteis e partículas em suspensão.

Por reter temporariamente as partículas suspensas no ar e absorver alguns gases nocivos aos seres humanos, a vegetação é capaz de amenizar os efeitos indesejáveis da poluição nas cidades. (NOWAK, 1994; LLARDENT, 1982).

\footnotetext{
${ }^{1}$ Estudo apresentado pela Profa. Dra. Maria Regina Alves Cardoso no Seminário Metrópoles: Políticas, Planejamento e Gestão em Saúde e Ambiente, realizado na Faculdade de Saúde Pública da Universidade de São Paulo em 31/05/2011.
} 
A taxa de remoção de poluentes depende da quantidade destes na atmosfera, do vigor e porte da vegetação, do tipo e densidade de galhos e folhas e de condições climáticas (SPIRN, 1995; NOWAK, 1994; FALCÓN, 2007), sendo variável entre espécies e entre indivíduos da mesma espécie (MASCARÓ, 2010). Estudos conduzidos na cidade de Chicago (EUA) verificaram que árvores de grande porte são capazes de remover 60 a 70 vezes mais poluentes que as árvores menores (NOWAK, 1994). É importante ressaltar que quando os contaminantes atmosféricos são excessivos eles também podem prejudicar a vegetação.

Apesar de a vegetação possuir grande contribuição na remoção de poluentes da atmosfera, sua dispersão depende ainda do fluxo dos ventos no nível da rua para gerar a mistura com as camadas de ar menos poluído. Em ruas com vegetação muito densa, a dispersão pode ficar comprometida pela diminuição dos ventos, sendo importante considerar este efeito em ruas de tráfego intenso (GIVONI, 1998).

Outra importante influência da vegetação na composição atmosférica é a capacidade de fixação e produção de determinados gases, como o sequestro e armazenamento de $\mathrm{CO}_{2}$ na biomassa vegetal, que ocorre durante o crescimento das plantas.

Apesar de reduzir as quantidades de $\mathrm{CO}_{2}$ e de partículas suspensas no ar, a vegetação é responsável pela emissão de compostos orgânicos voláteis (COV) ${ }^{2}$. De acordo com Aquino (2006 apud SCHIRMER E QUADROS, 2010) a emissão de COV biogênicos (emitidos pela vegetação) é aproximadamente sete vezes maior que a emissão de COV antropogênicos (em termos globais). Os COV, juntamente com os óxidos de nitrogênio (NOx) e a radiação solar, são responsáveis pela formação do ozônio troposférico (i.e. aquele que ocorre na camada mais baixa da atmosfera), importante poluente responsável por problemas respiratórios e nevoeiros fotoquímicos, também chamados de smogs (do inglês smoke, fumaça, e fog, neblina).

Por esse motivo, na cidade de São Paulo é comum que as estações de monitoramento do ar localizadas no Parque do Ibirapuera e na Cidade Universitária, locais densamente vegetados, registrem altos níveis de concentração de ozônio.

\footnotetext{
${ }^{2}$ De acordo com Schirmer e Quadros (2010) compostos orgânicos compreendem todos os compostos que, à exceção do metano, possuam carbono e hidrogênio, sendo os COV aqueles facilmente vaporizados às condições de temperatura e pressão ambientes.
} 
A emissão de COV pela vegetação varia de acordo com a espécie e o metabolismo da planta, a temperatura do ar, a temperatura das folhas, a umidade, a densidade foliar, a radiação solar, a concentração de $\mathrm{CO}^{2}$ e de poluentes no ar (SCHIRMER e QUADROS, 2010). Apesar de a vegetação ser a principal responsável, em termos globais, pelas emissões de compostos orgânicos voláteis, para que a transformação em ozônio ocorra são necessários os óxidos de nitrogênio, emitidos principalmente pelos automóveis.

\section{POLUIÇÃO DA ÁGUA E DO SOLO}

De acordo com Morinaga (2007), em áreas urbanas o solo é o meio mais afetado pela contaminação, superando o nível de contaminantes das águas dos rios e córregos. Sua poluição apresenta baixa mobilidade de contaminantes (ainda que estes possam passar para as águas subterrâneas) e está relacionada principalmente às regiões industrializadas e aos locais de disposição de resíduos.

Por meio da absorção dos contaminantes pelas raízes e/ou concentração em sua biomassa, a vegetação pode atuar na remoção ou imobilização desses contaminantes. As plantas são capazes de remover metais pesados, pesticidas e outros contaminantes do ambiente. Trata-se da fitorremediação, técnica caracterizada pela utilização de processos naturais das plantas para a remoção de poluentes do solo, de lodos, de sedimentos e das águas. De baixo custo e fácil implementação, esta técnica é indicada para grandes áreas com pequeno nível de contaminação e que não apresentem riso iminente à saúde (MORINAGA, 2007).

Morinaga (2007) alerta que o transporte de contaminantes para a superfície, absorvidos pelas raízes e conduzidos às partes aéreas das plantas, pode ocasionar a introdução desses contaminantes na cadeia alimentar da fauna local.

\section{TEMPERATURA E UMIDADE}

As temperaturas mais altas verificadas em áreas densamente construídas quando comparadas a seu entorno rural vegetado configuram o fenômeno conhecido como "ilha de calor". 
Esse fenômeno é predominantemente noturno, sendo as maiores diferenças de temperatura entre áreas urbanas e não urbanas verificadas em noites de céu claro e pouco vento. (GIVONI, 1998).

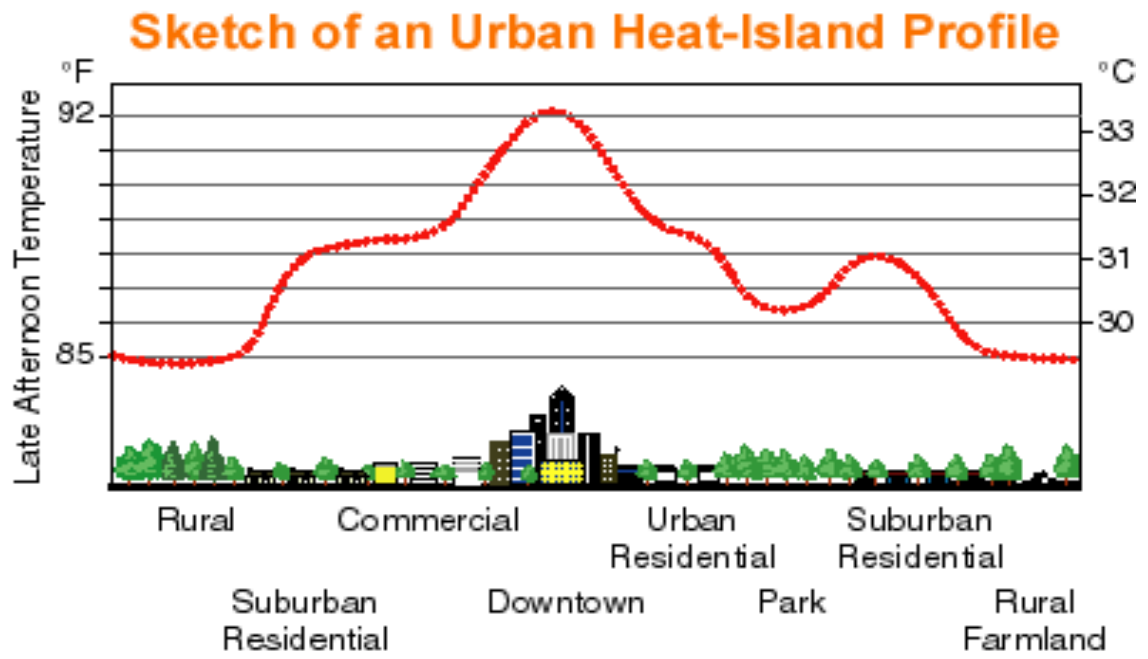

Figura 2 - Ilha de calor urbana. Fonte: Bearkeley Lab.

Algumas características das estruturas urbanas, como a relação entre a largura das ruas e a altura dos edifícios, os tipos de materiais construtivos utilizados e a quantidade e localização das áreas verdes afetam a intensidade da ilha de calor (GIVONI, 1998; LOMBARDO, 1985).

De acordo com Lombardo (1985), as maiores temperaturas dos centros urbanos podem provocar uma alteração na distribuição de chuvas, fazendo com que ocorram de maneira mais intensa sobre as áreas mais densamente construídas. Essa dinâmica, aliada ao alto grau de impermeabilização de algumas cidades provoca o aumento das inundações.

Em seu estudo sobre a região metropolitana de São Paulo, Lombardo (1985) verificou diferenças de até $10^{\circ} \mathrm{C}$ entre o centro e as áreas rurais, sendo que as temperaturas mais altas foram medidas nas áreas mais densamente construídas e com pouca quantidade de vegetação e as temperaturas mais amenas nas regiões com maior concentração de espaços livres vegetados e junto aos reservatórios de água.

No ambiente urbano, a vegetação barra a radiação solar, evitando que ela incida sobre o solo e as construções, diminuindo assim o acúmulo e a irradiação de calor por essas superfícies. A radiação absorvida pela vegetação é utilizada para a fotossíntese 
e para a evapotranspiração; apenas uma porcentagem muito pequena é convertida em calor sensível (SANTAMOURIS, 2001).

Givoni (1998) ressalta que é durante o processo de evapotranspiração, e não durante a fotossíntese, que ocorre a maior parte do consumo de energia das plantas. Durante esse processo as folhas são resfriadas, assim como o ar ao redor delas, ao mesmo tempo em que ocorre o aumento de umidade do ar. A importância e o desejo de que esse processo ocorra dependem das condições de temperatura e umidade locais.

De acordo com Magalhães e Crispim (2003), o processo de evapotranspiração é responsável pelo consumo de $60 \%$ a $75 \%$ da energia solar incidente na vegetação, sendo que uma árvore isolada saudável e com bom suprimento de água pode transpirar 400 litros de água/dia.

Spangenberg (2009) alerta para o fato de que a definição das frações de absorção, transmissão e reflexão dos dosséis vegetais é mais complexa do que a dos materiais de construção devido à arquitetura da copa das árvores, à distribuição heterogênea de folhas, à diferença entre as espécies etc.

Labaki, et al. (2011) observam que a informação existente sobre o comportamento da transmissão da radiação solar através de árvores, isoladas ou agrupadas, é bastante reduzida, principalmente no que se refere às espécies da flora brasileira.

O impacto da vegetação no consumo de energia para aquecimento e resfriamento dos edifícios pode ser bastante significativo. Em relação ao resfriamento, a sombra produzida pela vegetação localizada próxima às paredes e janelas reduz o ganho de calor solar sem obstruir completamente a circulação de ar. Ademais, áreas gramadas ao redor dos edifícios reduzem a radiação solar refletida pelo solo e pavimentos, diminuindo também os ganhos de calor da edificação. Em relação à diminuição do consumo de energia para aquecimento, dependendo do arranjo de plantio e da localização da vegetação ela é capaz de diminuir a velocidade do vento ao redor das construções, minimizando assim as taxas de infiltração de ar (GIVONI, 1998).

Spangenberg (2009) ressalta que os benefícios proporcionados pelo sombreamento durante o verão podem se converter em desvantagens durante o inverno em determinados locais. Nessas situações, o plantio de espécies caducifólias pode maximizar os benefícios. 


\section{VENTILAÇÃO}

De acordo com Llardent (1982), as massas arbóreas conseguem reduções importantes na velocidade do vento, entre $20 \%$ e $50 \%$. Tais reduções ocorrem de maneira gradual e, ao contrário das barreiras sólidas, não provocam zonas de turbulências, sendo, portanto, mais eficientes. Segundo Givoni (1998), o impacto da vegetação no fluxo de ar ocorre com maior intensidade próximo ao solo e depende do arranjo de plantio e das espécies utilizadas.

O deslocamento do ar regula a sensação térmica, pois estimula a evaporação e as perdas de calor por convecção (MASCARÓ, 1996). Em climas quentes e úmidos, a redução da velocidade do vento pode gerar desconforto; porém, em climas frios é um dos fatores mais benéficos da vegetação (GIVONI, 1998).

Além do efeito de obstrução mencionado acima, a barreira vegetal possui outros três efeitos básicos: filtragem, deflexão e condução.
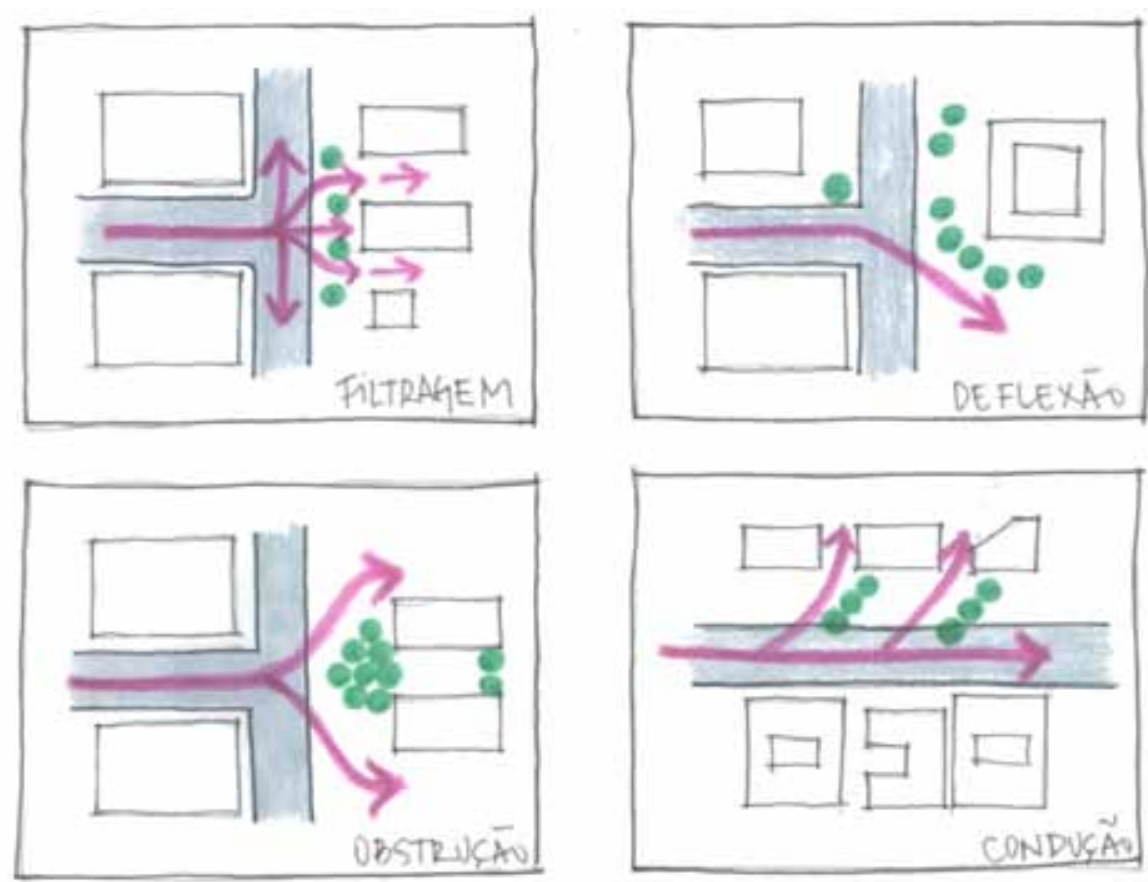

Figura 3 - Efeitos da barreira vegetal. Fonte: Elaboração própria baseada em Mascaró, 1996.

Acima de $1,5 \mathrm{~m} / \mathrm{s}$ e, sobretudo acima de $5 \mathrm{~m} / \mathrm{s}$, a incidência de vento diminui as diferenças de temperatura e umidade relativa do ar entre as áreas sombreadas e ensolaradas, sendo mais significativa em relação à umidade do que em relação à temperatura (MASCARÓ, 1996). 


\section{DRENAGEM}

O problema das inundações em áreas urbanas está diretamente relacionado à excessiva impermeabilização do solo, à escassez de áreas vegetadas e à canalização maciça de rios e córregos, medidas que em conjunto contribuem para o aumento da quantidade e da velocidade do escoamento superficial.

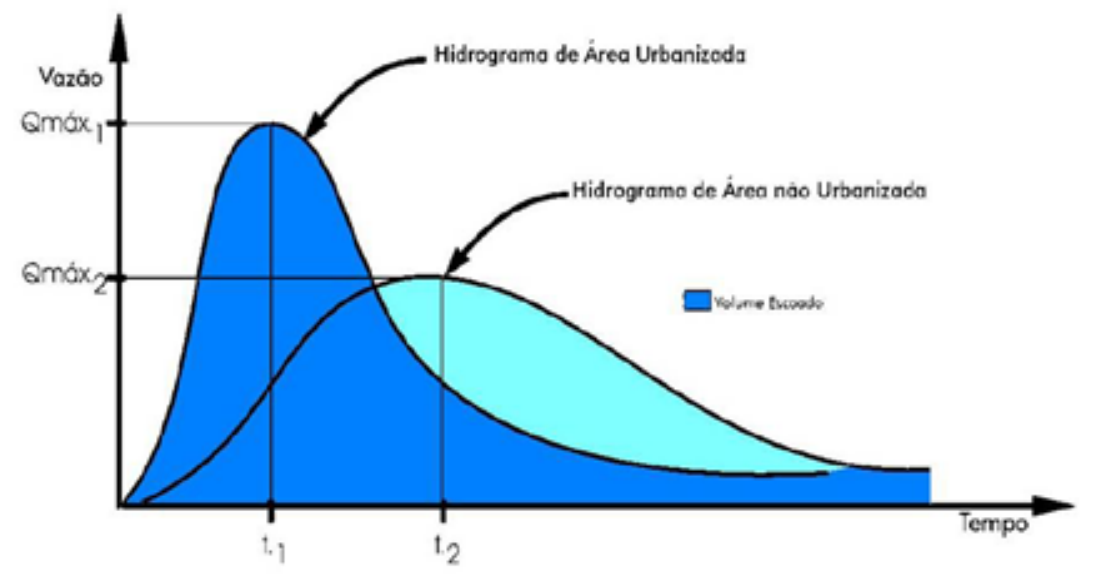

Figura 4 - Impacto da urbanização na vazão e no tempo do escoamento superficial. Fonte: Netto (2004).

A vegetação impacta a drenagem urbana por meio da retenção da água de chuva em sua copa, galhos e tronco, da contribuição para infiltração da água no solo, da proteção do solo ao ravinamento e da diminuição da velocidade do escoamento superficial (MAGNOLI,1982). A infiltração de água no solo depende diretamente do tipo de solo e não apenas da presença da vegetação.

[...] a distribuição, estrutura espacial, estrutura de ramificação e folhagem, densidade de 'arquitetura' foliar e da galharia, bem como a distribuição, em extensão e profundidade, do raizame tem influência direta na rapidez de formação da superfície do espelho d'água a escoar. Após o encharcamento a influência se relaciona somente à proteção do solo ao ravinamento (MAGNOLI, 1982, p.91).

Segundo a Agência Americana de Proteção Ambiental (EPA, 2003), a velocidade de escoamento num quarteirão urbanizado pode ser cinco vezes maior do que em áreas de mesmo tamanho com vegetação e solo exposto. A alta velocidade do escoamento aumenta a erosão e a quantidade de sedimentos carreados para os rios e córregos, diminuindo a vazão destes e provocando inundações (HOUGH, 1998). 
Llardent (1982) alerta para o fato de que a grama fornece porosidade ao solo apenas até $10 \mathrm{~cm}$ de profundidade e com o tempo as raízes podem se entrecruzar de tal maneira que deixam o solo compactado. Assim, uma superfície gramada pode não ser tão permeável quanto se imagina, evidenciando que a análise do tipo de solo e do tipo de vegetação a ser implantada é importante para determinar a contribuição da vegetação à drenagem urbana.

\section{ESTABILIDADE DO SOLO}

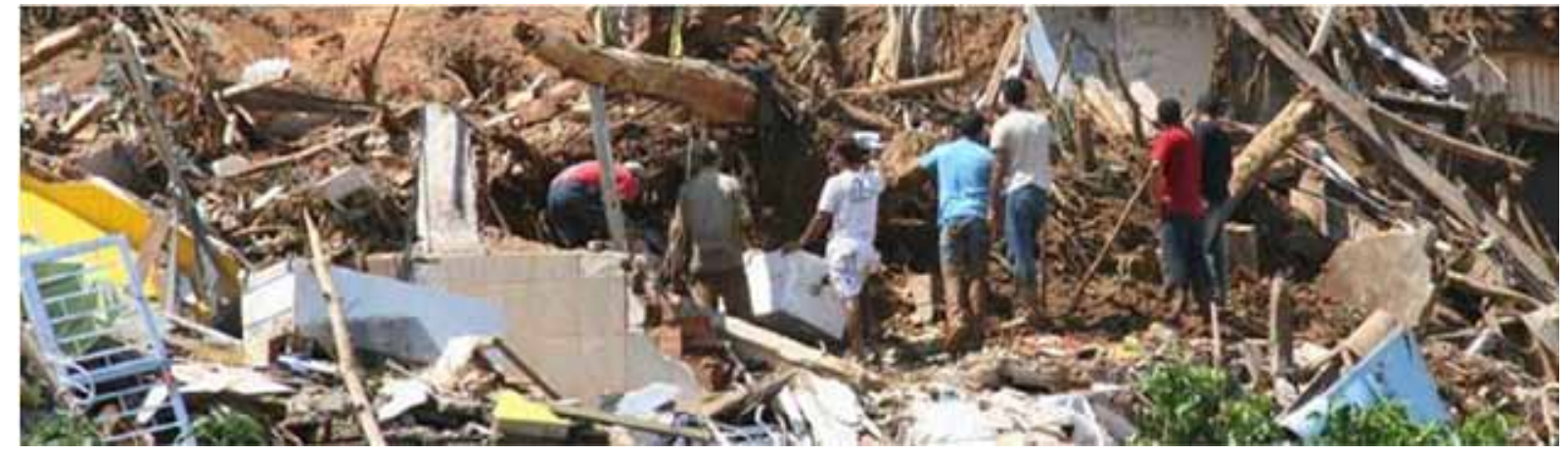

Figura 5 - Deslizamento de terra em área urbana. Fonte: R7 Notícias.

As intervenções urbanas, ao promoverem a impermeabilização parcial da superfície, modificam o regime hídrico do solo, soerguendo ou rebaixando o lençol freático. Tais alterações podem provocar a destruição das estruturas do solo e causar abatimentos em sua superfície (MANFREDINI, FERREIRA e QUEIROZ NETO, 2004).

Em grandes aglomerados urbanos, a estabilidade do solo é de fundamental importância para a segurança da população e das construções, estando relacionada também ao assoreamento de rios e córregos, como mencionado no item "drenagem".

A vegetação contribui para a manutenção da umidade do solo, atenuando o aquecimento e evitando a irradiação (LLARDENT, 1982). Quanto maior a temperatura do solo, maior é a sua oxidação e maior é a sua decomposição, gerando, assim, maior erosão em lençol e lixiviação (PENHALBER et al., 2004). Ademais, a presença de vegetação pode diminuir o carregamento de materiais particulados durante chuvas intensas, dependendo da granulometria do solo, bem como amortecer a força do impacto da chuva, evitando a formação de sulcos ou ravinamento. 
Segundo Falcón (2007), a vegetação mais indicada para a fixação do solo são as gramíneas e os arbustos, pois suas raízes são pouco profundas e bastante densas. Já a vegetação arbórea é indicada para diminuir o impacto da força da chuva no solo.

\section{RUÍDO}

A atenuação do ruído pela vegetação é um benefício bastante citado; porém, mesmo em áreas densamente arborizadas a redução é pequena, especialmente em médias e baixas frequências, devendo-se principalmente ao aumento da distância entre a fonte de ruído e as edificações e à diminuição da intensidade do vento (GIVONI, 1998).

Diversos trabalhos citam diferentes níveis de redução conseguidos com a utilização de barreira vegetal; porém, tais reduções podem ser consequência do aumento da distância da fonte, efeitos da topografia, da direção e da intensidade dos ventos etc. Para Givoni (1998), apesar da pequena capacidade na redução dos níveis de ruído, a vegetação tem um importante papel psicológico, ao atuar como barreira visual, uma vez que se o ruído não é visível ele se torna psicologicamente menos perceptível.

\section{SAÚDE E BEM-ESTAR HUMANO}

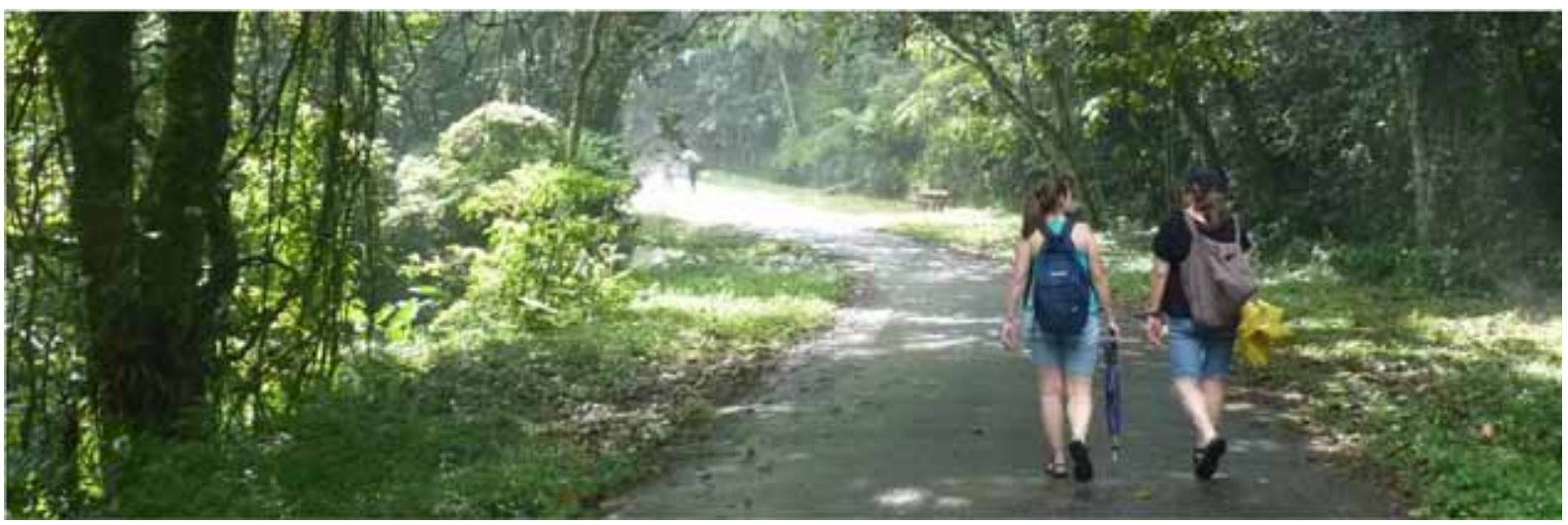

Figura 6 - Trilha da Pedra Grande. Parque Estadual da Cantareira. Imagem da autora, mai. 2011.

Um dos principais aspectos associados às áreas verdes em meio urbano é seu uso recreacional e esportivo. A promoção de áreas de convívio social e de áreas contemplativas está relacionada ao bem-estar e saúde da população, diminuindo o estresse, a ansiedade e a depressão, e contribuindo no tratamento de pacientes hospitalizados (GIVONI, 1998; ULRICH, 1984; ULRICH, et al., 1991). 
Ao analisar pacientes em internação hospitalar após cirurgia Ulrich (1984) verificou que aqueles que estavam em quartos com janelas voltadas para áreas verdes tinham menor período de internação em relação àqueles cujas janelas estavam voltadas para edifícios. Além do menor tempo de internação, esses pacientes utilizavam menor dose de medicamentos e tinham avaliação mais favorável por parte das enfermeiras.

Diversas instituições de saúde estão incorporando "jardins de cura" em suas instalações. Esses jardins, que devem incentivar o convívio e o apoio social e oferecer a possibilidade de atividades físicas e contato com a natureza, podem desempenhar papel complementar aos tratamentos medicamentosos, diminuindo o stress, a ansiedade, a pressão sanguínea e a insônia, aumentando, assim, a qualidade de vida dos pacientes (TEXAS A\&M UNIVERSITY, 2003).

Os benefícios verificados nos jardins dos hospitais também se estendem às áreas vegetadas e aos espaços livres da cidade, porém desde que estes recebam manutenção, utilização e segurança adequados, oferecendo condições propícias para o desenvolvimento de atividades sociais; do contrário, essas áreas podem aumentar a sensação de insegurança gerando stress.

Para Lima (1996), o desenho da vegetação na cidade também deve considerar as diversas formas de apropriação dos espaços urbanos. Dependendo da situação, uma cobertura arbórea densa pode não ser desejável, como no caso de locais de grande aglomeração de pessoas ou lugares onde o sombreamento é indesejável.

Ao atenuar a poluição da atmosfera, da água e do solo e contribuir com o conforto térmico dos espaços abertos, a vegetação também contribui com a saúde humana. Os benefícios associados à estabilidade dos solos e amortecimento de enchentes pela vegetação também podem ser considerados como benéficos ao bem-estar dos habitantes da cidade.

\section{BIODIVERSIDADE ${ }^{3}$}

De acordo com Spirn (1995), a transformação dos ambientes silvestres em centros urbanos inviabilizou a manutenção de habitats para a fauna local, pois os resquícios

\footnotetext{
${ }^{3}$ De acordo com a Lei Federal $n^{\circ}$ 9.985/2000 biodiversidade, ou diversidade biológica é: "a variabilidade de organismos vivos de todas as origens, compreendendo, dentre outros, os ecossistemas terrestres, marinhos e outros ecossistemas aquáticos e os complexos ecológicos de que fazem parte; compreendendo ainda a diversidade dentro de espécies, entre espécies e de ecossistemas" (Art. $2^{\circ}$ da Lei Federal $n^{\circ}$ 9.985/2000).
} 
de vegetação nativa são poucos e dispersos. Assim, as espécies que prosperam no empobrecido ambiente urbano são espécies oportunistas, que adaptaram o seu comportamento à uma paisagem dominada pelos homens.

Porém, o mosaico de ambientes encontrados em São Paulo ainda oferece locais adequados ao abrigo, à alimentação e à reprodução da fauna, sendo significativo o número de espécies cadastradas na cidade (SÃO PAULO (CIDADE), SVMA, 2004).

A adaptação da flora e da fauna ao hostil ambiente urbano, bem como a preservação de áreas vegetadas, são fatores que colaboram para a existência de um número significativo de espécies vegetais e animais em algumas cidades. De acordo com o último Inventário da Fauna do Município de São Paulo (SÃO PAULO (CIDADE), SVMA, 2010), a cidade possui 700 espécies catalogadas, das classes: Malacostraca (caranguejo e lagostim), Arachnida (aranhas), Insecta (borboletas e grilo), Osteichthyes (peixes), Amphibia (rãs, sapos e pererecas), Reptilia (cágados, crocodilos, lagartos e cobras), Aves e Mammalia. Em relação à flora, segundo dados do Herbário Municipal de São Paulo ${ }^{4} \mathrm{a}$ cidade possui 4.037 espécies vegetais de 231 diferentes famílias.

A urbanização não afeta somente a diversidade biológica pela diminuição das áreas vegetadas e alteração dos habitat naturais, mas também pela criação de novos habitats que proporcionam o aparecimento de espécies indesejáveis ao convívio humano, como insetos e ratos (SÃO PAULO (CIDADE), 2008).

Se a manutenção de áreas vegetadas em meio urbano colabora positivamente para a manutenção da biodiversidade, a falta de conexões entre essas áreas e as dificuldades de gestão das áreas que não possuem proteção efetiva tornam-se um impasse a ser vencido para a proteção de animais e plantas. Nesse sentido, o Instituto Socioambiental (INSTITUTO SOCIOAMBIENTAL, 2008) recomenda as seguintes ações para a ampliação da proteção à biodiversidade: ampliação e manutenção das áreas efetivamente protegidas; fiscalização das áreas preservadas; manejo da biodiversidade e apoio à pesquisa para diminuição de lacunas de conhecimento.

Penhalber et al. (2004) mencionam a dependência entre a fauna e a flora. Segundo os autores, a fauna silvestre é de suma importância para a sobrevivência das espé-

${ }^{4}$ Disponível em: http://biodiversidade.prefeitura.sp.gov.br/FormsPublic/p04Flora.aspx 
cies vegetais e vice-versa, sendo que a qualidade do verde depende da manutenção da fauna.

Abordar o papel da vegetação na cidade a partir dos benefícios fornecidos aos seres humanos pode ser considerado uma visão antropocêntrica caso uma perspectiva mais abrangente na gestão dos recursos não seja analisada. De acordo com Lima (1996), a nossa relação com a natureza necessita mudanças. Não apenas o bem-estar humano é importante, mas igualmente a utilização dos recursos em ritmos e escalas nas quais se propiciem condições temporais e espaciais para uma regeneração da própria natureza (LIMA, 1996).

\section{CUSTOS, DESVANTAGENS OU INCONVENIENTES ASSOCIADOS À VEGETA- ÇÃO URBANA}

A presença da vegetação em meio urbano proporciona diversos benefícios socioambientais aos habitantes da cidade, como mencionado nos itens anteriores. Contudo, existem custos diretos e indiretos que devem ser considerados no seu planejamento e implantação.

Como aponta Spirn (1995), a vegetação urbana tem que conviver com enormes pressões biológicas, físicas e químicas que dificultam sua sobrevivência no ambiente urbano, fazendo com que as árvores na cidade vivam menos. Estudos desenvolvidos nos Estados Unidos pela American Forest Association concluíram que a sobrevida média de uma árvore urbana (plantada em regiões centrais) é de apenas 13 anos, tempo insuficiente para que atinja um porte capaz de desempenhar de forma plena os benefícios citados nos itens anteriores. (ROTERMUND, MOTTA e ALMEIDA, 2012).

Essa diminuição da sobrevida das árvores em meio urbano deve-se à sua conflituosa convivência com a massa edificada da cidade e seus habitantes.

As árvores das ruas [...] levam uma vida marginal, suas raízes presas entre as fundações das edificações e das ruas, enroscadas entre as linhas de telefones, eletricidade, gás e água, e envoltas por um solo tão compacto e infértil como o concreto. Seus troncos são entalhados pelos pára-choques dos automóveis, correntes de bicicletas e até pelas grades instaladas para protegê-las. Seus galhos são podados pelos ônibus. Folhas e cascas são 
tostadas no calor refletido pelo calçamento e pelos muros ou condenadas a uma sombra perpétua pelos edifícios adjacentes. As raízes são encharcadas ou ressecadas pelo excesso ou pela falta de água; em qualquer caso, sua capacidade de fornecer nutrientes essenciais à árvore é drasticamente reduzida. [...] O fato de a árvore de ruas e calçadas sobreviver de alguma forma é mais surpreendente do que o de ser tão curta sua média de vida (SPIRN, 1995, p.193 e 194).

Parte dos custos associados à presença de vegetação nas cidades advém justamente dos conflitos mencionados por Spirn (1995).

\section{CUSTOS DIRETOS}

A implantação e a perpetuação da vegetação em áreas urbanas demandam diversas ações de planejamento e administração a cargo principalmente do poder público municipal. Ações de plantio e manutenção, incluindo podas, irrigação e varrição, demandam pessoal habilitado e equipamentos específicos.

A integração com a infraestrutura existente na cidade é um dos problemas mais recorrentes associados à vegetação urbana. A interferência com as redes aéreas, a proximidade com as edificações, gerando sombreamento excessivo e insegurança, o entupimento de bueiros e bocas de lobo pelas folhas das árvores, a interferência com a iluminação pública e com a sinalização, muitas vezes encoberta por galhos, além de danos a pisos e pavimentos causados por raízes superficiais são alguns dos problemas verificados.

A queda de árvores é um dos maiores transtornos que acometem as cidades brasileiras durante o período de chuvas (que, podem ser mais intensas nas áreas urbanas). De acordo com reportagem veiculada no jornal O Estado de São Paulo, segundo dados da AES Eletropaulo, "mais da metade dos casos de apagões na cidade de São Paulo acontece por culpa de queda de árvores ou galhos que se enroscam na fiação" (O ESTADO DE SÃO PAULO, 2011).

\section{CUSTOS INDIRETOS}

Spangenberg (2009) cita como custos indiretos relacionados à presença de vegetação nas cidades a possível diminuição da dispersão de poluentes ocasionada pela 
diminuição da intensidade dos ventos, a diminuição dos níveis de luz natural provocada pelo sombreamento da vegetação, o desconforto térmico no inverno, o possível aumento da umidade nos edifícios e as questões ligadas à segurança, que, como mencionado no item Saúde e Bem-Estar Humano, podem estar associadas à falta de manutenção e uso das áreas vegetadas.

\section{CONSIDERAÇÕES FINAIS}

Quantitativamente, os benefícios associados à vegetação citados nos itens anteriores dependem da densidade das folhas, dos tipos de folhas e galhos (e.g. folhas pilosas ou lisas, grandes ou pequenas etc.), do porte da vegetação e de sua localização. Essas características, com exceção da localização, variam conforme a idade, a espécie e a época do ano.

Spangenberg (2009) cita a área de cobertura vegetal e a área foliar como parâmetros-chave para a avaliação dos benefícios da floresta urbana. De acordo com Nowak (1994), a maioria dos benefícios da vegetação urbana cresce com o aumento da área foliar.

A área foliar varia conforme a espécie, a arquitetura da copa, o microclima, as condições de crescimento da árvore e com as estações do ano, sendo considerada um parâmetro dinâmico. Consequentemente, cada avaliação da área foliar descreve um momento específico (SPANGENBERG, 2009).

De acordo com Givoni (1998) o efeito da vegetação no clima das áreas urbanas depende da relação entre área vegetada (pública ou privada) e área construída, sendo mais intenso na área vegetada e em seu entorno imediato. Dessa forma, é mais significativo para o clima das áreas urbanas um maior número de áreas com dimensões reduzidas do que poucas áreas verdes de grandes dimensões.

Os custos diretos associados à presença de vegetação são, aparentemente, mais fáceis de serem quantificados e, como são mais perceptíveis no cotidiano da população urbana, acabam, muitas vezes, deturpando a imagem da árvore na cidade, que fica conhecida apenas pelos transtornos que causa. "Custos e benefícios calculados sem uma avaliação do sistema como um todo e dos processos que o impelem subestimam invariavelmente o valor da natureza na cidade" (SPIRN, 1995, p. 255). 
Como mencionado por Lima (1996), faz-se necessária uma visão mais abrangente da questão da vegetação urbana, que contemple aspectos ecológicos, paisagísticos, culturais e sociais, aliando as necessidades da vegetação para um desenvolvimento pleno e a diversidade de espaços urbanos e suas diferentes apropriações. 


\section{REFERÊNCIAS BIBLIOGRÁFICAS}

AGÊNCIA BRASIL. [ ], 2010. 1 Fotografia color. Disponível em: <ecourbana.wordpress. com>. Acesso em 20/dez./2011.

AQUINO, C. A. B. Identificação de compostos orgânicos voláteis (COVs) emitidos por florestas na região amazônica. 2006. 106f. Dissertação (Mestrado em Física e Meio Ambiente) - Universidade Federal do Mato Grosso, Cuiabá, 2006.

BERKELEY LAB. Heat Island Group. Disponível em: <http://heatisland.Idl.gov>. Acesso em: 05/jan./2012.

EPA - ENVIRONMENTAL PROTECTION AGENCY. Protecting Water Quality from Urban Runoff, 2003. Disponível em: <http://cfpub.epa.gov/npstbx/files/NPS_Urban-facts_ final.pdf $>$. Acesso em: 15/set./2011.

FALCÓN, A. Espacios verdes para una ciudad sostenible: planificación, proyecto, mantenimiento y gestión. Barcelona: Gustavo Gili, 2007.

FERREIRA, L. S. Manejo da vegetação na cidade de São Paulo: supressão e compensação. O caso do distrito da Vila Andrade. Dissertação (Mestrado) - Faculdade de Arquitetura e Urbanismo da Universidade de São Paulo (FAUUSP). São Paulo, 2012.

GIVONI, B. Climate Considerations in Building and Urban Design. New York: John Wiley \& Sons, 1998.

HOUGH, M. Naturaleza y ciudad. Planificación Urbana y Processos Ecológicos. Barcelona: Gustavo Gili, 1998.

ISA - INSTITUTO SOCIOAMBIENTAL. Além do Concreto: contribuições para a proteção da biodiversidade paulistana. São Paulo: [s.n.], 2008.

LABAKI, L. C. et al. Vegetação e conforto térmico em espaços urbanos abertos. Fórum Patrimônio - Ambiente Construído e Patrimônio Sustentável, v. 4, n. 1, 2011. Disponível em: <http://www.forumpatrimonio.com.br/index.php>. Acesso em: 05/jan./2011.

LIMA, C. P. C. D. S. A natureza na cidade. A natureza da cidade. Tese (Doutorado) Faculdade de Arquitetura e Urbanismo da Universidade de São Paulo (FAUUSP). São Paulo. 1996.

LLARDENT, L. R.-A. Zonas Verdes y Espacios Libres en la Ciudad. Madrid: Instituto de Estudios de Administración Local, 1982. 
LOMBARDO, M. A. Ilha de Calor nas Metrópoles: O exemplo de São Paulo. São Paulo: Hucitec, 1985.

MAGALHÃES, L. M. S.; CRISPIM, A. A. Vale a pena plantar e manter árvores e florestas na cidade? Ciência Hoje $n^{\circ} 193$, p. 64 a 68, maio 2003.

MAGNOLI, M. M. Espaços livres e urbanização: uma introdução a aspectos da paisagem metropolitana. Tese (Livre Docencia) - Faculdade de Arquitetura e Urbanismo da Universidade de São Paulo (FAUUSP). São Paulo. 1982.

MANFREDINI, S.; FERREIRA, R. P. D.; QUEIROZ NETO, J. P. D. Reflexões sobre o solo urbano. In: CARLOS, A. F. A.; OLIVEIRA, A. U. D. Geografias de São Paulo. A Metrópole do século XXI. São Paulo: Contexto, 2004.

MASCARÓ, J. L.; MASCARÓ, L. Vegetação Urbana. Porto Alegre: Masquatro, 2010. MASCARÓ, L. Ambiência Urbana. 3. ed. Porto Alegre: Masquatro Editora, 1996.

MORINAGA, C. M. Recuperação de Áreas Contaminadas. Um novo desafio para projetos paisagísticos. Dissertação (Mestrado) - Faculdade de Arquitetura e Urbanismo da Universidade de São Paulo (FAUUSP). São Paulo. 2007.

NETTO, O. M. D. C. Técnicas de Minimização da Drenagem de Águas Pluviais. Gerenciamento do Saneamento em Comunidades Organizadas. São Paulo: [s.n.]. 2004. Disponível em: <www.etg.ufmg.br/tim2/auladrenagem.ppt>. Acesso em 15/jul/2007.

NOWAK, D. J. Understanding the Structure. Journal of Forestry, n. 92, p. 42 - 46, 1994.

O ESTADO DE SÃO PAULO. Metade das falhas é provocada por queda de árvores. São Paulo, 14 abr. 2011. Cidade, Metrópole, P.C3.

PENHALBER, E. D. F. et al. Aspectos Urbanísticos de Espaços Públicos e Áreas Verdes. In: ROMERO, M. D. A.; JÚNIOR, A. P.; BRUNA, G. C. Panorama Ambiental da Metrópole de São Paulo. São Paulo: Sigrus, 2004. Cap. 14, p. 305-349.

R7 NOTÍCIAS. Portal de notícias da Central Record de Comunicações. Disponível em:<www.r7.com>. Acesso em: 20/dez./2011.

ROTERMUND, R. M.; MOTTA, V. P.; ALMEIDA, V. D. S. Estudo sobre a perda de mudas arbóreas plantadas no sistema viário da cidade de São Paulo. Revista da Sociedade Brasileira de Arborização Urbana, Piracicaba, 2012. No prelo. 
SÃO PAULO (CIDADE) SECRETARIA DO VERDE E DO MEIO AMBIENTE. Inventário da Fauna do Município de São Paulo. In: Diário Oficial da Cidade de São Paulo (Suplemento). São Paulo: Imprensa Oficial, 21 mai. 2010.

Ações Locais para a Biodiversidade da Cidade de São Paulo. São Paulo. 2008.

Atlas Ambiental do Município de São Paulo - O Verde, o Território, o Ser Humano: Diagnóstico e Bases para a Definição de Políticas para as Áreas Verdes no Município de São Paulo. Coordenação de Patrícia Marra Sepe e Harmi Takiya. São Paulo: SVMA, 2004.

SÃO PAULO (CIDADE) SECRETARIA MUNICIPAL DO VERDE E DO MEIO AMBIENTE; INSTITUTO DE PESQUISAS TECNOLÓGICAS. GEO Cidade de São Paulo: panorama do meio ambiente urbano. Brasília: PNUMA, 2004.

SCHIRMER, W. N.; QUADROS, M. E. Compostos orgânicos voláteis biogênicos emitidos a partir de vegetação e seu papel noozônio troposférico urbano. REVSBAU v.5 n.1, Piracicaba, p. 25-42, Mar 2010. Disponível em:< http://www.revsbau. esalq.usp.br/artigos_cientificos/artigo102-publicacao.pdf >. Acesso em 7/ago./2011.

SPANGENBERG, J. Nature in Megacities. Tese (Doutorado) - Bauhaus Universität. Weimar. 2009.

SPIRN, A. W. O jardim de granito: a natureza no desenho da cidade. São Paulo: Editora da Universidade de São Paulo, 1995.

TEXAS A\&M UNIVERSITY. Gardens Have The Potential To Improve Health, Research Shows. ScienceDaily, 24 novembro 2003. Disponível em: <http://www.sciencedaily.com/releases/2003/11/031124071045.htm >. Acesso em 11/set./2011.

ULRICH, R. S. View through a window may influence recovery from surgery. Science, v. 224, p. 420-421, 1984.

ULRICH, R. S. et al. Stress recovery during exposure to natural and urban environments. Journal of Environmental Psychology, v. 11, p. 201-230, 1991. 